\title{
Quantitative motor unit potential analysis and nerve conduction studies for detection of subclinical peripheral nerve dysfunction in patients with compensated liver cirrhosis
}

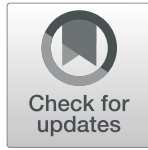

\author{
Mostafa M. Elkholy ${ }^{1 *}$ (D) and Ragaey A. Eid ${ }^{2}$ (D)
}

\begin{abstract}
Background: Peripheral neuropathy is an underestimated problem of compensated liver cirrhosis despite its negative effect on quality of life. The aim was to assess the role of meticulous electrophysiological screening (nerve conduction responses and quantitative motor unit potential analysis) of subclinical peripheral nerve dysfunction in patients with compensated cirrhosis and also to explore its relations with different characteristics of liver disease. Severity of cirrhosis was assessed by Child-Pugh and albumin-bilirubin (ALBI) scores.

Results: Prevalence of hepatic neuropathy $(\mathrm{HN})$ was $82 \%$. It involved sensory and motor fibers (66\%), and its pathophysiology was axonal (53.7\%) or mixed axonal and demyelinating (46.3). The most sensitive discriminating tests were ulnar sensory conduction velocity (area under curve $(A \cup C)=0.915)$ and peak latency $(A \cup C=0.887)$, peroneal motor conduction velocity ( $A \cup C=0.885$ ), ulnar distal motor latency ( $A \cup C=0.842$ ), and first dorsal interosseous number of phases ( $A \cup C=0.736$ ). HN showed significant correlation with the severity of liver disease assessed by both child $(P=0.029)$ and $A L B I(P=0.016)$ scores and also correlated with the low serum albumin level $(P=0.001)$.

Conclusions: Subclinical mild axonal polyneuropathy is very common in post-hepatitis C compensated cirrhosis picked up by meticulous electrophysiological testing, and it is related to severity of liver cirrhosis and low serum albumin level.
\end{abstract}

Keywords: Liver cirrhosis, Hepatic neuropathy, Electrodiagnostic evaluation, Quantitative EMG, Motor unit potential

\section{Background}

Liver cirrhosis is one of the major causes of morbidity and mortality with variable burden and causes among different geographical distribution. In 2017, cirrhosis caused more than 1.32 million deaths globally and SubSaharan Africa had the highest age-standardized death rate among GBD (Global Burden of Diseases, Injuries, and Risk Factors Study) super-regions [1]. Unfortunately,

\footnotetext{
* Correspondence: mostafaelkholy@med.bsu.edu.eg

'Department of Clinical Neurophysiology (Neuro-Diagnostic and Research Center), Faculty of Medicine, Beni-Suef University, Beni-Suef, Egypt Full list of author information is available at the end of the article
}

Egypt has one of the highest global burdens of hepatitis $\mathrm{C}$ virus ( $\mathrm{HCV})$ infections; it is estimated that prevalence of $\mathrm{HCV}$ is around 4.5 to $6.7 \%$ [2].

Peripheral neuropathy (PN) is one of the common complications of chronic liver disease (CLD) with a variable prevalence ranging between 19 and $80 \%$ in previous studies depending on clinical assessment and routine nerve conduction studies [3-5].

Hepatic neuropathy $(\mathrm{HN})$ has a negative impact on the activity of daily living and quality of life and needs to be more focused upon. Moreover, there is controversy regarding the correlation between causes, severity of CLD, prevalence, and characteristics of PN [6]. 
Hepatic neuropathy is one of the leading causes of frailty which is widely recognized as a potent prognostic indicator of both disability and mortality in cirrhosis [7].

Early screening and detection of subclinical PN among these patients are important for their management and lowering its socioeconomic burden. To our knowledge, most of the previous studies addressing this aspect focused on clinical assessment and limited nerve conduction studies. Moreover, some studies lacked a control group which is very important because PN associated with CLD is more prevalent in old age.

The aim of this study is to clarify the importance of good and meticulous electrophysiological screening for early detection of peripheral nerve dysfunction in a sample of patients with compensated liver cirrhosis using objective quantitative motor unit potential (MUP) analysis and nerve conduction studies. Moreover, we aim to explore any significant correlation between characteristics of liver cirrhosis and hepatic neuropathy.

\section{Methods}

\section{Participants}

This cross-sectional case-control study was conducted on 90 individuals divided into two groups (patients and control) in Beni-Suef University hospitals during the period from October 2020 till February 2021. The study protocol was approved from the local ethical committee of faculty of Medicine, Beni-Suef University and an informed written consent was obtained from all participants before enrollment in the study.

The patient group included 50 patients diagnosed with post-hepatitis $\mathrm{C}$ liver cirrhosis based on clinical assessment, biochemical liver profile, and abdominal ultrasonography. They were recruited from the hepatology outpatient clinic or those attending the GIT Endoscopy unit to screen for varices in Beni-Suef University hospitals. All patients were previously treated from HCV by sofosbuvir-based regimens offered by The Egyptian national viral hepatitis treatment program and all of them achieved sustained virological response.

All cirrhotic patients were compensated based on Child-Pugh score: (Patients with preserved liver functions without ascites or clinical hepatic encephalopathy) [8].

Patients with other identified causes of peripheral neuropathy (diabetes, uremia, thyroid disorders, alcoholism, autoimmune disease, neurodegenerative disorders, paraneoplastic syndromes, cryoglobulinemic vasculitis, or neurotoxic drug intake) were excluded from the study. Patients with decompensated cirrhosis (ChildPugh score C) were also excluded.

The control group included 40 healthy volunteers age and sex matched with the selected patients.

\section{Methods}

Patients were subjected to the following:

(1) Clinical assessment through full history taking, complete general and abdominal examination with particular emphasis on the stigmata of chronic liver disease and signs of vasculitis.

(2) Laboratory evaluation: CBC, ESR, urine analysis, liver function tests, kidney function tests, hepatitis markers, thyroid profile, serum electrolytes, alphafetoprotein (AFP), and PCR for HCV RNA. Based on the clinical as well as laboratory parameters, Child-Pugh score and albumin-bilirubin (ALBI) score were calculated [9].

(3) Abdominal ultrasonography: to confirm the presence of cirrhosis. Characteristic findings were the nodular liver surface, round edge, parenchymal nodularity. Detection of splenomegaly, ascites, and portosystemic collaterals was also possible. Doppler US was done for the hepatic and portal veins, hepatic artery, and intra-abdominal portosystemic collaterals [10].

(4) Neurological assessment: we used neuropathy symptom and change (NSC) score to test and grade the presence of PN. NSC score consists of questions regarding the type of pain or slight illness, location and time of symptoms, arousal from the sleep and maneuvers that relieved symptoms. An NSC of 3-4 points were considered a mild neuropathy symptom, 5-6 points as medium neuropathy symptom, and 7-9 points as severe neuropathy symptom [11].

(5) Electrophysiological assessment: All study participants were evaluated by electrodiagnostic studies that were carried out in the Clinical Neurophysiology department in Beni-Suef University hospitals using Nihon Kohden Electromyography machine (Neuropack X1, EMG/ EP MEB-2300, Japan). All electrodiagnostic studies were performed by the same investigator with an acceptable experience (more than 10 years in performing nerve conduction and EMG tests).

\section{(a) Nerve conduction studies (NCS)}

These studies were performed using surface recording and stimulating electrodes according to the standard electrode positions and distances mentioned in Preston and Shapiro [12], and with room temperature kept at $\left(28-33{ }^{\circ} \mathrm{C}\right)$ and ensuring well-defined and artifact-free responses. Filter settings were as follows: $(10 \mathrm{~Hz}-5 \mathrm{kHz}$ for motor studies, $20 \mathrm{~Hz}-2 \mathrm{kHz}$ for sensory studies). 
The studied nerves were bilateral ulnar and right median nerves (sensory and motor responses) in upper limbs and bilateral common peroneal, right posterior tibial (motor responses), right superficial peroneal, and left sural nerves (sensory responses) in lower limbs.

The measured parameters were distal motor latency, negative peak duration, onset to peak compound muscle action potential amplitude and conduction velocity for motor responses, peak latency, onset to peak sensory nerve action potential amplitude, and conduction velocity for sensory responses

(b) Quantitative electromyography (EMG) and motor unit potential (MUP) analysis

We used the disposable concentric EMG needle electrodes $(0.45 \mathrm{~mm}$ diameter, $45 \mathrm{~mm}$ length, Nihon Kohden). Filter settings were $2 \mathrm{~Hz}-10 \mathrm{kHz}$.

MUP selection parameters were as follows: (rise time: $50 \mu \mathrm{V}$ for turns; $15 \mu \mathrm{V}$ for phase level/ MUP onset and end point: slope $30 \mu \mathrm{v} / \mathrm{ms}$; level $100 \mu \mathrm{V} /$ match threshold $94 \%$ ).

The muscles selected for analysis were left extensor hallucis longus in lower limb and right first dorsal interosseous in upper limb because these are among the most distal extremity muscles common to be affected early in distal polyneuropathy.

We selected a sample of 20 motor unit action potentials (MUAP) from each muscle at the mild to moderate activation level through 3-4 insertion sites.

The evaluated parameters were the amplitude, duration, area, number of phases and turns, muscle thickness (area/amplitude in $\mathrm{mV}$ ), and size index $[2 \times \log 10$ (amplitude in $\mathrm{mV}$ ) + area/amplitude in $\mathrm{mV}$ ] averaged across the selected 20 MUPs for each muscle [13].

(6) Evaluation of peripheral nerve dysfunction: We proposed electrodiagnostic criteria to specify the presence of polyneuropathy if three or more of the measured parameters were abnormally exceeding the upper or lower limits of normality measured as mean \pm 2 SD of the age-matched control group. To assess the severity of electrodiagnostic affection, the following "neuropathy electrodiagnostic severity score" (NESS) was proposed (Table 1).
(7) Data management and statistical analysis: Data were analyzed using SPSS (statistical package for the social science software) Version 25.0. Quantitative variables were expressed by mean, standard deviation, and $95 \%$ confidence interval or by median and interquartile range (IQR) (as appropriate) and were compared using independent $\mathrm{t}$ test or Mann-Whitney U test (as appropriate). Qualitative variables were expressed by number and percent and were compared by chi-square test. Pearson correlation was used to correlate two continuous variables; otherwise, Spearman correlation was used. Diagnostic and accuracy testes were computed using MedCalc version (14.8.1). In all tests, $\mathrm{p}$ value was considered significant if less than 0.05 .

\section{Results}

Demographic, clinical characteristics, and laboratory findings of the participants

The patient group included 50 patients with chronic liver disease (35 males) and the mean age was $60.2 \pm 8.7$ years. The control group included 40 participants matched with the patients in age and sex distribution ( $P$ $=0.869$ and 0.115 respectively).

In all patients, liver cirrhosis was secondary to chronic hepatitis $\mathrm{C}$ and all of them were compensated. None of the patients had muscle swelling or wasting, lower limb edema, or ascites. Their clinical characteristics and comorbidity are demonstrated in Table 2 and laboratory findings in Supplemental Table 1.

\section{Nerve conduction findings}

There was a statistically significant difference between the study groups in motor responses (ulnar nerve distal latency, forearm conduction velocity, and common peroneal conduction velocity) and sensory responses (ulnar SNAP latency, amplitude and conduction velocity, median and sural SNAP amplitudes) (Table 3).

Twenty-one patients showed absent superficial peroneal sensory responses and fourteen patients showed absent sural sensory responses. On the contrary only one individual of the control group showed absent superficial peroneal response and another three showed absent sural responses.

Table 1 Neuropathy electrodiagnostic severity score (NESS)

\begin{tabular}{lll}
\hline Score & Number of abnormal values* & Degree of abnormality \\
\hline 0 & $<3$ & Not exceeding $90 \%$ of ULN/LLN \\
1 & $3-5$ & $70-90 \%$ of ULN/LLN \\
2 & $6-8$ & Exceeding $70 \%$ of ULN/LLN \\
3
\end{tabular}

ULN, upper limit of normal; LLN, lower limit of normal

Scores: 2-3: mild; 4-5: moderate; 6: severe

*Absent sensory response is equivalent to 2 abnormal values 
Table 2 Clinical characteristics of the patients

\begin{tabular}{|c|c|c|c|}
\hline & & Patients (n & \\
\hline & & Frequency & Percentage \\
\hline Child score & $A$ & 46 & $92 \%$ \\
\hline & B & 4 & $8 \%$ \\
\hline & C & 0 & $0 \%$ \\
\hline ALBI grade & 1 & 24 & $48 \%$ \\
\hline & 2 & 24 & $48 \%$ \\
\hline & 3 & 2 & $4 \%$ \\
\hline NSC Scale & No pain & 21 & $42 \%$ \\
\hline & Mild & 16 & $32 \%$ \\
\hline & Moderate & 10 & $20 \%$ \\
\hline & Severe & 3 & $6 \%$ \\
\hline Smoking & Yes & 16 & $32 \%$ \\
\hline & No & 34 & $68 \%$ \\
\hline Hypertension & Yes & 13 & $26 \%$ \\
\hline & No & 37 & $74 \%$ \\
\hline
\end{tabular}

$A L B I$, albumin-bilirubin; NSC, neuropathy symptom and change

There were reported focal demyelinating median neuropathy at the wrist (carpal tunnel syndrome) in 6 patients ( 1 mild, 3 moderate, and 3 severe) and in 7 individuals of the control group, and all these values were excluded from analysis of nerve conduction findings. Another individual in the control group showed electrophysiological findings of significant L4/5 root affection and his common peroneal nerve conduction findings were also excluded from analysis. Two patients showed severely affected right common peroneal motor responses and gave history of old ankle fracture and their values were excluded from analysis.

\section{Quantitative MUP analysis findings}

There was a statistically significant difference between the study groups in duration, number of phases and turns of both tested muscles (FDI and EHL), and muscle thickness index of EHL muscle (Table 4).

\section{Prevalence of peripheral neuropathy in the cirrhotic patients}

To accomplish this issue, the healthy controls were divided into two equal age subgroups (the first was 60 years or less and the second group was more than 60 years) and then the upper and lower limits of normal cutoff values were measured using mean \pm 2SD for each of the recorded electrophysiological (NCS and QEMG) parameters.

By individual comparing the patients to the agespecific cutoff values, the prevalence of hepatic neuropathy was $82 \%$ (HN was defined if there was more than two abnormal EDX parameters) and their electrodiagnostic severity was assessed by the proposed "neuropathy electrodiagnostic severity score" (NESS) (Fig. 1).

Analysis of the HN patients showed that most of them had affected both motor and sensory fibers (65.9\%) and its pathophysiology was either pure axonal degeneration $(53.7 \%)$ or mixed axonal and demyelination (46.3\%).

\section{Diagnostic accuracy of QEMG and NCS}

By using the same defining criteria of HN (more than two abnormal parameters) and comparing the two electrodiagnostic techniques, the sensitivity of QEMG was 62.1 compared to NCS. The prevalence of $\mathrm{HN}$ in the patient group using NCS alone, QEMG, or combining both methods were $58 \%, 48 \%$, and $82 \%$ respectively (Supplemental Tables 2 and 3).

We selected a set of the most sensitive electrodiagnostic parameters to compare their diagnostic accuracy using ROC curve analysis. The most sensitive EDX parameters to detect $\mathrm{HN}$ were ulnar sensory conduction velocity, ulnar sensory distal latency, common peroneal motor conduction velocity, and ulnar distal motor latency respectively (Table 5 ).

\section{Correlation between the clinical characteristics and electrodiagnostic findings of the patients:}

There was a statistically significant direct relation between age, child score, and severity of HN. Albumin level and ALBI score showed a statistically significant inverse relation with severity of $\mathrm{HN}$ and nerve conduction findings (Table 6). Moreover, smoking had a significant relation with incidence of $\mathrm{HN}(\mathrm{P}=0.023)$.

\section{Correlation between nerve conduction and QMUP analysis findings}

There was a statistically significant direct relation between the ulnar distal motor latency, FDI duration, number of phases and EHL duration (Supplemental Table 4).

\section{Discussion}

This study hypothesized that patients with liver cirrhosis are at increased risk of developing peripheral neuropathy, so we aimed to highlight the importance of good screening and early detection of subclinical polyneuropathy in patients with compensated cirrhosis and to explore any significant association between characteristics of liver cirrhosis and peripheral nerve dysfunction.

All patients in our study were post-hepatitis $C$ being the most common cause of liver cirrhosis in Egypt. Moreover, most of them had mild liver cirrhosis based on Child-Pugh classification ( $92 \%$ were Child-A). We excluded patients with decompensated cirrhosis due to their frailty and disability caused by chronic malnutrition 
Table 3 Significant differences of nerve conduction findings between the two groups

\begin{tabular}{|c|c|c|c|c|c|c|c|c|}
\hline Parameter & Group & Mean & SD & Median & IQR & $95 \% \mathrm{Cl}$ for mean & $P$ value & $95 \% \mathrm{Cl}$ for difference \\
\hline \multirow[t]{2}{*}{ Right ulnar motor latency (ms) } & $\begin{array}{l}\text { Patients } \\
(\mathrm{n}=50)\end{array}$ & 3.4 & 0.45 & 3.3 & 0.5 & $\begin{array}{l}3.24 / \\
3.49\end{array}$ & $0.0338^{*}$ & $0.02 / 0.48$ \\
\hline & $\begin{array}{l}\text { Controls } \\
(n=40)\end{array}$ & 3.1 & 0.37 & 3.2 & 0.5 & $\begin{array}{l}2.94 / \\
3.29\end{array}$ & & \\
\hline \multirow[t]{2}{*}{ Left ulnar motor latency (ms) } & $\begin{array}{l}\text { Patients } \\
(\mathrm{n}=50)\end{array}$ & 3.1 & 0.41 & 3.15 & 0.4 & $\begin{array}{l}3.03 / \\
3.26\end{array}$ & $0.035^{*}$ & $0.02 / 0.43$ \\
\hline & $\begin{array}{l}\text { Controls } \\
(\mathrm{n}=40)\end{array}$ & 2.9 & 0.35 & 2.85 & 0.6 & $\begin{array}{l}2.76 / \\
3.09\end{array}$ & & \\
\hline \multirow[t]{2}{*}{$\begin{array}{l}\text { Left ulnar motor velocity } \\
(\mathrm{m} / \mathrm{s})\end{array}$} & $\begin{array}{l}\text { Patients } \\
(\mathrm{n}=50)\end{array}$ & 56.9 & 7.1 & 56.1 & 8.5 & $\begin{array}{l}54.96 / \\
59\end{array}$ & $0.011^{*}$ & $-8.59 /-1.13$ \\
\hline & $\begin{array}{l}\text { Controls } \\
(\mathrm{n}=40)\end{array}$ & 61.8 & 6.9 & 61.2 & 13.5 & $\begin{array}{l}58.57 / \\
65.11\end{array}$ & & \\
\hline \multirow[t]{2}{*}{ Right peroneal motor velocity $(\mathrm{m} / \mathrm{s})$} & $\begin{array}{l}\text { Patients } \\
(\mathrm{n}=48)\end{array}$ & 45.3 & 4.8 & 46.6 & 6.2 & $\begin{array}{l}45.56 / \\
48.42\end{array}$ & $0.019^{*}$ & $-5.39 /-0.49$ \\
\hline & $\begin{array}{l}\text { Controls } \\
(\mathrm{n}=40)\end{array}$ & 48.2 & 4 & 48.6 & 8 & $\begin{array}{l}46.61 / \\
50.39\end{array}$ & & \\
\hline \multirow[t]{2}{*}{ Left peroneal motor velocity $(\mathrm{m} / \mathrm{s})$} & $\begin{array}{l}\text { Patients } \\
(\mathrm{n}=50)\end{array}$ & 44.7 & 5.6 & 45.6 & 6 & $\begin{array}{l}44.47 / \\
47.76\end{array}$ & $0.043^{*}$ & $-5.55 /-0.09$ \\
\hline & $\begin{array}{l}\text { Controls } \\
(\mathrm{n}=39)\end{array}$ & 47.5 & 3.4 & 49.6 & 7 & $\begin{array}{l}45.69 / \\
49.44\end{array}$ & & \\
\hline \multirow[t]{2}{*}{ Right median sensory amplitude $(\mu \mathrm{V})$} & $\begin{array}{l}\text { Patients } \\
(\mathrm{n}=44)\end{array}$ & 21.1 & 9.9 & 19.4 & 13.4 & $\begin{array}{l}18.05 / \\
24.05\end{array}$ & $0.011^{*}$ & $-15.51 /-2.1$ \\
\hline & $\begin{array}{l}\text { Controls } \\
(n=33)\end{array}$ & 29.8 & 11.7 & 25.5 & 18.4 & $\begin{array}{l}22.41 / \\
37.31\end{array}$ & & \\
\hline \multirow[t]{2}{*}{ Right ulnar sensory velocity $(\mathrm{m} / \mathrm{s})$} & $\begin{array}{l}\text { Patients } \\
(\mathrm{n}=50)\end{array}$ & 46.9 & 5.5 & 47 & 8.5 & $\begin{array}{l}45.34 / \\
48.56\end{array}$ & $0.016^{*}$ & $-6.39 /-0.68$ \\
\hline & $\begin{array}{l}\text { Controls } \\
(\mathrm{n}=40)\end{array}$ & 50.5 & 4.9 & 49.5 & 5.5 & $\begin{array}{l}48.19 / \\
52.79\end{array}$ & & \\
\hline \multirow[t]{2}{*}{ Right ulnar sensory amplitude $(\mu \mathrm{V})$} & $\begin{array}{l}\text { Patients } \\
(n=50)\end{array}$ & 18.1 & 10.5 & 15.25 & 11.3 & $\begin{array}{l}15.04 / \\
21.17\end{array}$ & $0.030^{*}$ & \\
\hline & $\begin{array}{l}\text { Controls } \\
(n=40)\end{array}$ & 23.5 & 10.3 & 20.45 & 16.8 & $\begin{array}{l}18.69 / \\
28.34\end{array}$ & & \\
\hline \multirow[t]{2}{*}{ Left ulnar sensory latency (ms) } & $\begin{array}{l}\text { Patients } \\
(n=50)\end{array}$ & 3.03 & 0.34 & 3 & 0.4 & $\begin{array}{l}2.93 / \\
3.12\end{array}$ & $0.026^{*}$ & $0.02 / 0.35$ \\
\hline & $\begin{array}{l}\text { Controls } \\
(n=40)\end{array}$ & 2.8 & 0.22 & 2.8 & 0.3 & $\begin{array}{l}2.74 / \\
2.94\end{array}$ & & \\
\hline \multirow[t]{2}{*}{ Left ulnar sensory velocity (m/s) } & $\begin{array}{l}\text { Patients } \\
(\mathrm{n}=50)\end{array}$ & 47.1 & 5.98 & 47 & 7.5 & $\begin{array}{l}45.36 / \\
48.76\end{array}$ & $0.013^{*}$ & $-6.57 /-0.81$ \\
\hline & $\begin{array}{l}\text { Controls } \\
(n=40)\end{array}$ & 50.7 & 3.79 & 50.5 & 5.5 & $\begin{array}{l}48.97 / \\
52.53\end{array}$ & & \\
\hline \multirow[t]{2}{*}{ Left ulnar sensory amplitude $(\mu \mathrm{V})$} & $\begin{array}{l}\text { Patients } \\
(\mathrm{n}=50)\end{array}$ & 20.8 & 12.41 & 20 & 14.4 & $\begin{array}{l}17.31 / \\
24.37\end{array}$ & $0.038^{*}$ & \\
\hline & $\begin{array}{l}\text { Controls } \\
(n=40)\end{array}$ & 25.3 & 8.67 & 24.2 & 12.3 & $\begin{array}{l}21.21 / \\
29.33\end{array}$ & & \\
\hline \multirow[t]{2}{*}{ Left sural sensory amplitude $(\mu \mathrm{V})$} & $\begin{array}{l}\text { Patients } \\
(\mathrm{n}=36)\end{array}$ & 9.8 & 4.21 & 9.3 & 4 & $\begin{array}{l}8.39 / \\
11.24\end{array}$ & $0.016^{*}$ & \\
\hline & $\begin{array}{l}\text { Controls } \\
(n=37)\end{array}$ & 13.6 & 6.22 & 11.8 & 8.5 & $\begin{array}{l}10.4 / \\
16.8\end{array}$ & & \\
\hline
\end{tabular}

$S D$, standard deviation; IQR, interquartile ratio; $C l$, confidence interval *Significant $P$ value $<0.05$ 
Table 4 Significant differences of quantitative MUP findings between the two groups

\begin{tabular}{|c|c|c|c|c|c|c|c|c|}
\hline Parameter & Group & Mean & SD & Median & IQR & $95 \% \mathrm{Cl}$ for mean & $P$ value & 95\% $\mathrm{Cl}$ for difference \\
\hline \multirow[t]{2}{*}{ Right FDI Duration (ms) } & $\begin{array}{l}\text { Patients } \\
(n=50)\end{array}$ & 10.19 & 1.35 & 10.2 & 1.6 & $\begin{array}{l}9.8 / \\
10.58\end{array}$ & $0.000^{*}$ & $1.02 / 2.42$ \\
\hline & $\begin{array}{l}\text { Controls } \\
(n=40)\end{array}$ & 8.47 & 1.24 & 8.6 & 2.4 & $\begin{array}{l}7.89 / \\
9.05\end{array}$ & & \\
\hline \multirow[t]{2}{*}{ Right FDI number of Phases } & $\begin{array}{l}\text { Patients } \\
(n=50)\end{array}$ & 3.56 & 0.57 & 3.4 & 0.8 & $\begin{array}{l}3.39 / \\
3.724\end{array}$ & $0.001^{*}$ & \\
\hline & $\begin{array}{l}\text { Controls } \\
(n=40)\end{array}$ & 3.09 & 0.33 & 3.1 & 0.4 & $\begin{array}{l}2.94 / \\
3.24\end{array}$ & & \\
\hline \multirow[t]{2}{*}{ Right FDI number of Turns } & $\begin{array}{l}\text { Patients } \\
(n=50)\end{array}$ & 3.13 & 0.71 & 3 & 0.99 & $\begin{array}{l}2.93 / \\
3.34\end{array}$ & $0.004^{*}$ & \\
\hline & $\begin{array}{l}\text { Controls } \\
(n=40)\end{array}$ & 2.65 & 0.4 & 2.6 & 0.68 & $\begin{array}{l}2.47 / \\
2.84\end{array}$ & & \\
\hline \multirow[t]{2}{*}{ Left EHL Duration (ms) } & $\begin{array}{l}\text { Patients } \\
(n=50)\end{array}$ & 11.53 & 1.53 & 11.7 & 1.7 & $\begin{array}{l}11.09 / \\
11.97\end{array}$ & $0.000^{*}$ & $0.82 / 2.45$ \\
\hline & $\begin{array}{l}\text { Controls } \\
(n=39)\end{array}$ & 9.89 & 1.48 & 10.1 & 2.3 & $\begin{array}{l}9.18 / \\
10.61\end{array}$ & & \\
\hline \multirow[t]{2}{*}{ Left EHL number of Phases } & $\begin{array}{l}\text { Patients } \\
(n=50)\end{array}$ & 3.91 & 0.475 & 3.8 & 0.6 & $\begin{array}{l}3.773 / \\
4.043\end{array}$ & $0.014^{*}$ & $0.06 / 0.53$ \\
\hline & $\begin{array}{l}\text { Controls } \\
(n=39)\end{array}$ & 3.61 & 0.31 & 3.5 & 0.5 & $\begin{array}{l}3.46 / \\
3.76\end{array}$ & & \\
\hline \multirow[t]{2}{*}{ Left EHL number of Turns } & $\begin{array}{l}\text { Patients } \\
(n=50)\end{array}$ & 3.76 & 0.81 & 3.75 & 1.19 & $\begin{array}{l}3.53 / \\
3.99\end{array}$ & $0.025^{*}$ & \\
\hline & $\begin{array}{l}\text { Controls } \\
(n=39)\end{array}$ & 3.32 & 0.59 & 3.1 & 0.56 & $\begin{array}{l}3.03 / \\
3.61\end{array}$ & & \\
\hline \multirow[t]{2}{*}{ Left EHL Thickness } & $\begin{array}{l}\text { Patients } \\
(n=50)\end{array}$ & 1.4 & 0.27 & 1.39 & 0.34 & $\begin{array}{l}1.32 / \\
1.48\end{array}$ & $0.047^{*}$ & $0.002 / 0.27$ \\
\hline & $\begin{array}{l}\text { Controls } \\
(n=39)\end{array}$ & 1.27 & 0.18 & 1.27 & 0.19 & $\begin{array}{l}1.18 / \\
1.35\end{array}$ & & \\
\hline
\end{tabular}

$F D I$, first dorsal interosseous; $E H L$, extensor hallucis longus; $S D$, standard deviation; $I Q R$, interquartile ratio; $C l$, confidence interval. * Significant $\mathrm{P}$ value $<0.05$

and muscle wasting. To assess the neuropathy symptoms, we used a subjective questionnaire (NSC) and it revealed that $42 \%$ of the patients were asymptomatic and $52 \%$ had mild to moderate pain and paresthesia.

We conducted extensive electrophysiological assessment (sensory and motor nerve conduction studies of

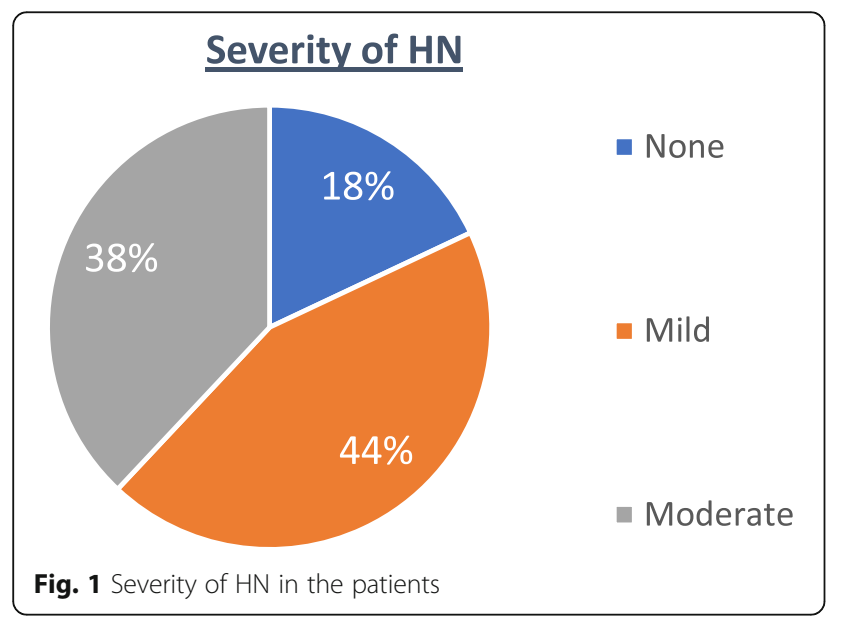

four limbs and QMUP analysis of two distal muscles) and using the proposed defining criteria of $\mathrm{HN}$ (more than two abnormal values), the prevalence of $\mathrm{HN}$ in our patients was $82 \%$. The pattern of peripheral nerve dysfunction was almost axonal degeneration (or mixed axonal and demyelinating) and involved both motor and sensory fibers and ranged from mild to moderate affection.

Most previous studies showed a mixed pattern of peripheral nerve involvement (axonal and demyelinating, sensorimotor affection) in agreement with our findings $[4,6$, 14]; however, other studies showed histopathologic evidence of segmental demyelination and remyelination in sural nerves of patients with hepatic neuropathy $[15,16]$.

The inter-group comparison revealed that cirrhotic patients had significantly abnormal nerve conduction finings (most commonly ulnar and peroneal distal motor latency and conduction velocity, ulnar sensory latency, amplitude, and conduction velocity, in addition to absent lower limb sensory responses in a significant proportion of the patients).

In reviewing the literature, there is a large controversy regarding the prevalence of $\mathrm{HN}$ (ranging from 20 to 63\% 
Table 5 Diagnostic accuracy of different electrodiagnostic parameters using ROC curve analysis

\begin{tabular}{|c|c|c|c|c|c|c|c|}
\hline Parameter & AUC & $95 \% \mathrm{Cl}$ for $\mathrm{AUC}$ & $P$ value & Youden index $\mathrm{J}$ & Associated criterion & Sensitivity & Specificity \\
\hline Left ulnar SNAP conduction velocity & 0.915 & $\begin{array}{l}0.801 / \\
0.975\end{array}$ & $<0.0001^{*}$ & 0.762 & $\leq 47.8 \mathrm{~m} / \mathrm{sc}$ & 76.19 & 100 \\
\hline Left ulnar SNAP peak latency & 0.887 & $\begin{array}{l}0.765 / \\
0.959\end{array}$ & $<0.0001^{*}$ & 0.607 & $>2.8 \mathrm{~ms}$ & 85.71 & 75 \\
\hline Left peroneal CMAP conduction velocity & 0.885 & $\begin{array}{l}0.764 / \\
0.958\end{array}$ & $<0.0001^{*}$ & 0.732 & $\leq 48.3 \mathrm{~m} / \mathrm{s}$ & 85.71 & 87.5 \\
\hline Right ulnar CMAP latency & 0.842 & $\begin{array}{l}0.712 / \\
0.930\end{array}$ & $<0.0001^{*}$ & 0.613 & $>3.1 \mathrm{~ms}$ & 73.81 & 87.5 \\
\hline Right FDI number of phases & 0.736 & $\begin{array}{l}0.591 / \\
0.852\end{array}$ & $0.0057^{*}$ & 0.439 & $>3.7$ & 43.9 & 100 \\
\hline Right FDI duration & 0.733 & $\begin{array}{l}0.588 / \\
0.849\end{array}$ & $0.0375^{*}$ & 0.509 & $>10 \mathrm{~ms}$ & 63.41 & 87.5 \\
\hline Left EHL number of turns & 0.732 & $\begin{array}{l}0.586 / \\
0.848\end{array}$ & $0.0025^{*}$ & 0.494 & $>3.65$ & 61.9 & 87.5 \\
\hline Left ulnar CMAP conduction velocity & 0.726 & $\begin{array}{l}0.582 / \\
0.843\end{array}$ & 0.0704 & 0.554 & $\leq 65.2 \mathrm{~m} / \mathrm{s}$ & 92.86 & 62.5 \\
\hline Left EHL duration & 0.724 & $\begin{array}{l}0.578 / \\
0.842\end{array}$ & $0.016^{*}$ & 0.375 & $>11.8 \mathrm{~ms}$ & 50 & 87.5 \\
\hline Left ulnar SNAP amplitude & 0.719 & $\begin{array}{l}0.574 / \\
0.837\end{array}$ & 0.0826 & 0.5833 & $\leq 24.9 \mu \mathrm{V}$ & 83.33 & 75 \\
\hline Left EHL thickness & 0.693 & $\begin{array}{l}0.547 / \\
0.816\end{array}$ & $0.0144^{*}$ & 0.4762 & $>1.4286$ & 47.62 & 100 \\
\hline Right FDI number of turns & 0.613 & $\begin{array}{l}0.463 / \\
0.749\end{array}$ & 0.3092 & 0.2866 & $>3$ & 53.66 & 75 \\
\hline Left sural SNAP amplitude & 0.607 & $\begin{array}{l}0.431 / \\
0.765\end{array}$ & 0.354 & 0.25 & $\leq 6.7 \mu \mathrm{V}$ & 25 & 100 \\
\hline Left EHL number of phases & 0.563 & $\begin{array}{l}0.413 / \\
0.704\end{array}$ & 0.4371 & 0.2143 & $>4.3$ & 21.43 & 100 \\
\hline
\end{tabular}

$A U C$, area under curve; $C l$, confidence interval; SNAP, sensory nerve action potential; $C M A P$, compound muscle action potential; $F D I$, first dorsal interosseous; EHL, extensor hallucis longus. ${ }^{*}$ Significant $\mathrm{P}$ value $<0.05$

based on clinical findings and from 18 to $73 \%$ based on electrophysiological studies) which may be explained by the different approaches in defining the presence of neuropathy and the different spectrum of the selected cirrhotic patients due to different etiologies and disease severity [3-6].

The higher prevalence in our study could be attributed to the extensive approach in electrophysiological testing of sensory and motor nerves in all limbs together with the use of quantitative MUP analysis which offers a more objective way in assessment of peripheral nerve motor fibers and muscles compared to the qualitative and subjective approach of routine EMG test.

This quantitative approach is carried out through analysis of basic and derived metrics extracted from a group of selected MUPs from the tested muscles. To our knowledge, most previous studies which evaluated the hepatic-related polyneuropathy have only focused on routine nerve conduction or autonomic function testes and no one used quantitative MUPs analysis in cirrhotic patients.
In the current study, the prevalence of $\mathrm{HN}$ was higher when using the combined electrophysiological methods (NCS and QEMG) than using a single modality (58\% and $48 \%$ respectively). This combined approach may serve for early detection of any subtle or subclinical peripheral nerve dysfunction in the compensated cirrhotic patients.

Moreover, the results of comparing different electrophysiological parameters using ROC curve analysis reported that the most sensitive parameters were (in order) ulnar sensory distal conduction velocity and peak latency, common peroneal conduction velocity and ulnar distal motor latency. These sensitive measures together with lower limb sensory responses could be used as a rapid screening tool to detect cirrhotic patients with polyneuropathy. In concordance with these results, the peroneal, ulnar, and sural nerve conduction responses were among the mostly discriminating nerves of $\mathrm{HN}$ in previous studies [4].

In our study, patient age and the severity of liver disease (assessed by both child and ALBI scores) were found to have a significant direct mild to moderate 
Table 6 Correlation between clinical, laboratory profile, and electrodiagnostic findings of the patients

\begin{tabular}{|c|c|c|c|c|c|c|c|c|c|c|c|c|}
\hline & & NESS & RULNML & LULNMC & LULNSL & LULNSC & LULNSA & LPERMC & RFDID & RFDIP & LEHLD & LEHLP \\
\hline \multirow[t]{3}{*}{ Age } & $r$ & $.308^{*}$ & 0.202 & -0.148 & 0.225 & -0.239 & $-.310^{*}$ & $-.340^{*}$ & -0.101 & $.337^{*}$ & 0.014 & $.283^{*}$ \\
\hline & $P$ & 0.03 & 0.160 & 0.306 & 0.116 & 0.095 & 0.029 & 0.016 & 0.488 & 0.018 & 0.921 & 0.047 \\
\hline & $n$ & 50 & 50 & 50 & 50 & 50 & 50 & 50 & 49 & 49 & 50 & 50 \\
\hline \multirow[t]{3}{*}{ Albumin } & r & $-.440^{* *}$ & $-.372^{* *}$ & $.418^{* *}$ & $-.381^{* *}$ & $.374^{* *}$ & 0.203 & $.442^{* *}$ & $-.344^{*}$ & -0.255 & 0.004 & -0.141 \\
\hline & $P$ & 0.001 & 0.008 & 0.002 & 0.006 & 0.007 & 0.157 & 0.001 & 0.015 & 0.077 & 0.980 & 0.328 \\
\hline & $\mathrm{n}$ & 50 & 50 & 50 & 50 & 50 & 50 & 50 & 49 & 49 & 50 & 50 \\
\hline \multirow[t]{3}{*}{ Bilirubin } & r & -0.057 & -0.008 & 0.046 & -0.164 & 0.249 & 0.178 & 0.058 & 0.103 & 0.013 & 0.087 & -0.086 \\
\hline & $P$ & 0.693 & 0.958 & 0.750 & 0.256 & 0.081 & 0.217 & 0.690 & 0.483 & 0.929 & 0.547 & 0.553 \\
\hline & $\mathrm{n}$ & 50 & 50 & 50 & 50 & 50 & 50 & 50 & 49 & 49 & 50 & 50 \\
\hline \multirow[t]{3}{*}{ Platelets } & $r$ & $-.280^{*}$ & -0.121 & $.343^{*}$ & 0.041 & 0.051 & 0.245 & $.282^{*}$ & -0.125 & -0.023 & 0.074 & -0.101 \\
\hline & P & 0.049 & 0.401 & 0.015 & 0.778 & 0.726 & 0.086 & 0.047 & 0.393 & 0.876 & 0.609 & 0.487 \\
\hline & $n$ & 50 & 50 & 50 & 50 & 50 & 50 & 50 & 49 & 49 & 50 & 50 \\
\hline \multirow[t]{3}{*}{ Child score } & $r$ & $.309^{*}$ & 0.123 & -0.177 & 0.053 & -0.099 & -0.100 & $-.282^{*}$ & 0.200 & 0.232 & -0.158 & 0.127 \\
\hline & $P$ & 0.029 & 0.394 & 0.219 & 0.716 & 0.493 & 0.490 & 0.048 & 0.167 & 0.109 & 0.273 & 0.381 \\
\hline & $n$ & 50 & 50 & 50 & 50 & 50 & 50 & 50 & 49 & 49 & 50 & 50 \\
\hline \multirow[t]{3}{*}{ ALBI score } & $r$ & $-.339^{*}$ & $-.318^{*}$ & $.383^{* *}$ & -0.251 & $.281^{*}$ & 0.142 & $.354^{*}$ & -0.187 & -0.152 & 0.023 & -0.177 \\
\hline & $P$ & 0.016 & 0.024 & 0.006 & 0.079 & 0.048 & 0.325 & 0.012 & 0.198 & 0.296 & 0.874 & 0.220 \\
\hline & $n$ & 50 & 50 & 50 & 50 & 50 & 50 & 50 & 49 & 49 & 50 & 50 \\
\hline
\end{tabular}

NESS, neuropathy electrodiagnostic severity score; RULNML, right ulnar motor latency; LULNMC, left ulnar motor conduction velocity; LULNSL, left ulnar sensory latency; LULNSC, left ulnar sensory conduction velocity; LULNSA, left ulnar sensory amplitude; LPERMC, left peroneal motor conduction velocity; RFDID, right first dorsal interosseous duration, RFDIP, right first dorsal interosseous phases; $L E H L D$, left extensor hallucis longus duration; $L E H L P$, left extensor hallucis longus phases; $A L T$, alanine transaminase; $A S T$, aspartate; INR, international normalized ratio; $B M I$, body mass index; NSC, neuropathy symptom and change; $A L B I$, albuminbilirubin; $r$, correlation coefficient

* Correlation is significant at the 0.05 level, ** Correlation is significant at the 0.01 level

correlation with the severity of HN. Moreover, a significant positive correlation was found between smoking and incidence of $\mathrm{HN}$.

Similarly, Jain et al found that PN was higher in cirrhotic patients older than 60 years compared to the younger age but odds ratio for age was not statistically significant [6]. Moreover, Santoro et al. found in their large multi-center study a significant correlation between the old age and prevalence of $\mathrm{PN}$ in $\mathrm{HCV}$ population [17]. In a large screening study by Beghi et al., the prevalence of PN among healthy elderly people with no recognized risk factors was $1.6 \%$ compared to $10.9 \%$ in age-matched patients with non-alcoholic liver cirrhosis [18].

It is well known that elderly are at more risk of peripheral nerve dysfunction due to processes of denervation that occur with normal aging at accelerated rate beyond 60 years of age, and so, it may be difficult to discriminate the effects of normal aging from pathological conditions [19-21].

Turning now to the positive correlation between smoking and $\mathrm{HN}$, a similar relation was found in another study [6]. Moreover, Clair et al. concluded in their review a positive association between smoking and incidence of diabetic PN through its microvascular complications and its adverse effects such as systemic inflammation, oxidative stress, endothelial dysfunction, and the resulting hypoxemia [22].

If we moved to the relation between severity of liver cirrhosis and HN, previous studies showed contradictory results. While our finding of a positive interrelation accords with some studies [14, 23, 24], others showed no significant correlation [4-6].

It is interesting to find in this study a statistically highly significant inverse moderate correlation between the albumin level and the findings of most nerve conduction studies and FDI duration. The lower the albumin level, the more abnormal electrodiagnostic values. Few previous studies showed a similar relation between low serum albumin and autonomic neuropathy in cirrhotic patients [3, 25]. Moreover, other studies showed that low serum albumin level had adverse effects on nerve conduction outcomes and was significantly associated with the severity of polyneuropathy in patients with type $2 \mathrm{DM}[26,27]$.

The exact pathophysiology underlying $\mathrm{HN}$ is not well known; however, different mechanisms were suggested in the literature including the liver failure itself, primary causes of liver cirrhosis, or its common comorbidities. 
The significant correlation explored in this study between severity of liver disease, low serum albumin level, and $\mathrm{HN}$ increases the likelihood that the metabolic dysfunction caused by the chronic liver disease itself rather than its etiology is the primary pathogenetic factor of HN.

Hepatocellular damage leads to disordered metabolism, reduction of cellular oxidative processes, and accumulation of toxic substances. This disruption results in functional and toxic inhibition of nerve axonal membrane and a possible damage to Schwann cells $[16,28$, 29]. Moreover, alteration of nitrogen metabolism and disordered insulin metabolism were suggested to have a role in the pathogenesis of $\mathrm{HN}[28,29]$.

Another early theory of portosystemic shunting was introduced by Chopra et al. [28]; however, this theory could be criticized by Kardel at al. who found no significant differences in cirrhotic patients who undergone portocaval shunts [30].

$\mathrm{HCV}$ infection is another important independent risk factor for developing $\mathrm{HN}$ especially when associated with cryoglobulinemia [31, 32]. All patients of our study were secondary to HCV infection, and so the confounding effect of $\mathrm{HCV}$ generating $\mathrm{HN}$ could not be explored or compared to other etiologies of CLD. Other studies had addressed this issue. For example, Chaudry et al. found that the prevalence of HN was not significantly different between cirrhotic patients caused by HCV infection and other etiologies [24]. On the other hand, Cocito et al. found that HN was more prevalent in $\mathrm{HCV}$-related liver cirrhosis compared to other disease groups; however, they stated in their final conclusion that the primary cause of nerve damage could be the toxic and metabolic changes resulting from hepatic failure and that the association between neuropathy and $\mathrm{HCV}$ infection could be random [23].

$\mathrm{HCV}$-related $\mathrm{HN}$ was mostly explained by virustriggered immune-mediated mechanisms resulting in ischemic nerve damage through vascular and perivascular inflammation and axonal degeneration [33, 34]. Other studies hypothesized that the nerve dysfunction results from reduced vascular perfusion due to an imbalance between potent vasoconstrictors and vasodilators leading to nerve axonal hyperexcitability [35-37].

The significant relation of low serum albumin to HN highlights its role being the most abundant circulating protein in human plasma and has significant effect on peripheral nerve function through its important antiinflammatory and antioxidative functions. Given that inflammation and oxidative stress are important pathophysiologic processes involved in microvascular and peripheral nerve dysfunction, this may explain the significant effect of hypoalbuminemia on development of $\mathrm{HN}$ [38-41].
Our study had several strengths. First, it included a homogenous group of compensated cirrhotic patients secondary to $\mathrm{HCV}$ infection. Second, we excluded many confounding factors regarding etiologies and comorbidities of CLD aiming to strengthen the cause-and-effect relationship between CLD and PN. Third, we compared the patient group to healthy age-matched control group to minimize the confounding effect of old age. Lastly, we conducted extensive electrophysiological assessment which included for the first time QMUP analysis in a such group of patients. On the contrary, our study lacked assessment of small fiber neuropathy using autonomic functions and quantitative sensory tests.

\section{Conclusions}

Peripheral nerve dysfunction is a frequent complication in patients with compensated HCV-related liver cirrhosis. Hepatic-related neuropathy was almost subclinical, mild to moderate, mainly axonal and involved both sensory and motor fibers. Such HN could be picked up by meticulous electrophysiological testing and a simple highly sensitive set of nerve conduction tests could be used as screening for early detection, management, and lowering its socioeconomic burden. Finally, $\mathrm{HN}$ was related to the severity of liver cirrhosis and especially to the lower serum albumin level.

\section{Abbreviations \\ AFP: Alpha-fetoprotein; ALBI: Albumin-bilirubin; ALT: Alanine transaminase; AST: Aspartate; BMI: Body mass index; CBC: Complete blood count; \\ CLD: Chronic liver disease; DM: Diabetes mellitus; EDX: Electrodiagnostic; EHL: Extensor hallucis longus; FDI: First dorsal interosseous; GBD: Global Burden of Diseases; HCV: Hepatitis C virus; HN: Hepatic neuropathy; INR: International normalized ratio; IQR: Interquartile range; MUAP: Motor unit action potentials; NCS: Nerve conduction studies; NESS: Neuropathy electrodiagnostic severity score; NSC: Neuropathy symptom and change; PN: Peripheral neuropathy; QEMG: Quantitative electromyography; QMUP: Quantitative motor unit potential; SNAP: Sensory nerve action potential}

\section{Supplementary Information}

The online version contains supplementary material available at https://doi. org/10.1186/s41983-021-00348-7.

Additional file 1. Supplemental Table 1 Laboratory findings of the patients. Supplemental Table 2: Sensitivity of QEMG compared to NCS in detecting HN. Supplemental Table 3: Diagnostic accuracy of QMG compared to NCS in detecting HN. Supplemental Table 4: Correlation between different electrodiagnostic findings (NCS and QEMG).

\section{Acknowledgements}

Not applicable

\section{Authors' contributions}

Eid R. recruited the patients, collected, and revised the clinical data. Elkholy M. collected and analyzed the electrophysiological data, performed statistical analysis, and drafted the manuscript. Both authors shared in the idea and design of research, read, and approved the final manuscript. 


\section{Funding}

This research did not receive any specific grant from funding agencies in the public, commercial, or not-for-profit sectors.

\section{Availability of data and materials}

The datasets used and/or analyzed during the current study are available from the corresponding author on reasonable request.

\section{Declarations}

\section{Ethics approval and consent to participate}

The study protocol was approved from the local ethical committee of faculty of Medicine, Beni-Suef University (Approval number: FMBSUREC/03112020) and in accordance with the principles of Helsinki Declaration and an informed written consent was obtained from all participants before enrollment in the study.

\section{Consent for publication}

Not applicable

\section{Competing interests}

The authors declare that they have no competing interests.

\section{Author details}

${ }^{1}$ Department of Clinical Neurophysiology (Neuro-Diagnostic and Research Center), Faculty of Medicine, Beni-Suef University, Beni-Suef, Egypt. ${ }^{2}$ Department of Tropical Medicine, Faculty of Medicine, Beni-Suef University, Beni-Suef, Egypt.

\section{Received: 9 April 2021 Accepted: 25 June 2021}

Published online: 08 July 2021

\section{References}

1. GBD 2017 Cirrhosis Collaborators. The global, regional, and national burden of cirrhosis by cause in 195 countries and territories, 1990-2017: a systematic analysis for the Global Burden of Disease Study 2017. Lancet Gastroenterol Hepatol. 2020:5(3):245-66.

2. Doss W, Hermez J, Atta H, Jabbour J. Towards a hepatitis-free Egypt: is this achievable? East Mediterr Health J. 2018;24(7):609-10. https://doi.org/10.2 6719/2018.24.7.609.

3. Keresztes K, Istenes I, Folhoffer A, Lakatos PL, Horvath A, Csak T, et al. Autonomic and sensory nerve dysfunction in primary biliary cirrhosis. World J Gastroenterol. 2004;10(20):3039-43. https://doi.org/10.3748/wjg.v10.i20.303 9.

4. Kharbanda PS, Prabhakar S, Chawla YK, Das CP, Syal P. Peripheral neuropathy in liver cirrhosis. J Gastroenterol Hepatol. 2003;18(8):922-6. https://doi.org/10.1046/j.1440-1746.2003.03023.x.

5. Abdelkader NA, Zaky DZ, Afifi H, Saad WE, Shalaby SI, Mansour MA. Neuropathies in hepatitis C-related liver cirrhosis. Indian J Gastroenterol. 2014;33(6):554-9. https://doi.org/10.1007/s12664-014-0509-4.

6. Jain J, Singh R, Banait S, Verma N, Waghmare S. Magnitude of peripheral neuropathy in cirrhosis of liver patients from central rural India. Annals Ind Academy Neurol. 2014;17(4):409-107. https://doi.org/10.4103/0972-2327.144 012.

7. Lai JC, Dodge JL, MCCulloch CE, Covinsky KE, Singer JP. Frailty and the burden of concurrent and incident disability in patients with cirrhosis: a prospective cohort study. Hepatol Commun. 2020;4(1):126-33. https://doi. org/10.1002/hep4.1444.

8. Albers I, Hartmann H, Bircher J, Creutzfeldt W. Superiority of the Child-Pugh classification to quantitative liver function tests for assessing prognosis of liver cirrhosis. Scand J Gastroenterol. 1989;24(3):269-76. https://doi.org/10.31 09/00365528909093045.

9. Sofka CM. Non-invasive evaluation of liver cirrhosis using ultrasound. Ultrasound Q. 2010;26(2):115

10. Fragaki M, Sifaki-Pistolla D, Orfanoudaki E, Kouroumalis E. Comparative evaluation of $A L B I, M E L D$, and Child-Pugh scores in prognosis of cirrhosis: is ALBI the new alternative? Ann Gastroenterol. 2019;32(6):626-32. https://doi. org/10.20524/aog.2019.0417.

11. Xiong Q, Lu B, Ye H, Wu X, Zhang T, Li Y. The diagnostic value of neuropathy symptom and change score, neuropathy impairment score and Michigan neuropathy screening instrument for diabetic peripheral neuropathy. Eur Neurol. 2015;74(5-6):323-7. https://doi.org/10.1159/ 000441449.

12. Preston DC, Shapiro BE. Electromyography and neuromuscular disorders ebook: clinical-electrophysiologic correlations (Expert Consult-Online): Elsevier Health Sciences; 2012

13. Sonoo M, Stålberg E. The ability of MUP parameters to discriminate between normal and neurogenic MUPs in concentric EMG: analysis of the MUP "thickness" and the proposal of "size index". Electroencephalogr Clin Neurophysiol. 1993;89(5):291-303. https://doi.org/10.1016/0168-5597(93 )90068-Z.

14. Mittal M, Singh PK, Kurrian S. Study of prevalence and pattern of peripheral neuropathy in patients with liver cirrhosis. Int J Adv Med. 2017:4(4):1041-5. https://doi.org/10.18203/2349-3933.ijam20173228.

15. Knill-Jones RP, Goodwill CJ, Dayan AD, Williams R. Peripheral neuropathy in chronic liver disease: clinical, electrodiagnostic, and nerve biopsy findings. J Neurol Neurosurg Psychiatry. 1972;35(1):22-30. https://doi.org/10.1136/ jnnp.35.1.22.

16. Chari VR, Katiyar BC, Rastogi BL, Bhattacharya SK. Neuropathy in hepatic disorders. A clinical, electrophysiological, and histopathological appraisal. J Neurol Sci. 1977;31(1):93-111. https://doi.org/10.1016/0022-510X(77)90008-9.

17. Santoro L, Manganelli F, Briani C, Giannini F, Benedetti L, Vitelli E, et al. Prevalence and characteristics of peripheral neuropathy in hepatitis $C$ virus population. J Neurol Neurosurg Psychiatry. 2006;77(5):626-9. https://doi. org/10.1136/jnnp.2005.081570.

18. Beghi E, Monticelli L, Italian General Practitioner Study Group. Chronic symmetric symptomatic polyneuropathy in the elderly: a field screening investigation of risk factors for polyneuropathy in two Italian communities. J Clin Epidemiol. 1998;51(8):697-702. https://doi.org/10.1016/S0895-43 56(98)00039-0.

19. Bromberg MB. The motor unit and quantitative electromyography. Muscle Nerve. 2020;61(2):131-42. https://doi.org/10.1002/mus.26718.

20. Gilmore KJ, Morat T, Doherty TJ, Rice CL. Motor unit number estimation and neuromuscular fidelity in 3 stages of sarcopenia. Muscle Nerve. 2017:55(5): 676-84. https://doi.org/10.1002/mus.25394.

21. McNeil CJ, Doherty TJ, Stashuk DW, Rice CL. Motor unit number estimates in the tibialis anterior muscle of young, old, and very old men. Muscle Nerve. 2005;31(4):461-7. https://doi.org/10.1002/mus.20276.

22. Clair C, Cohen MJ, Eichler F, Selby KJ, Rigotti NA. The effect of cigarette smoking on diabetic peripheral neuropathy: a systematic review and metaanalysis. J Gen Intern Med. 2015;30(8):1193-203. https://doi.org/10.1007/s11 606-015-3354-y.

23. Cocito D, Maule S, Paolasso I. High prevalence of neuropathies in patients with end-stage liver disease. Acta Neurol Scand. 2010;122(1):36-40. https:// doi.org/10.1111/j.1600-0404.2009.01256.x.

24. Chaudhry V, Corse AM, O'Brian R, Cornblath DR, Klein AS, Thuluvath PJ. Autonomic and peripheral (sensorimotor) neuropathy in chronic liver disease: a clinical and electrophysiologic study. Hepatology. 1999;29(6): 1698-703. https://doi.org/10.1002/hep.510290630.

25. Hendrickse MT, Thuluvath PJ, Triger DR. Natural history of autonomic neuropathy in chronic liver disease. Lancet. 1992;339(8807):1462-4. https:// doi.org/10.1016/0140-6736(92)92042-E.

26. Li L, Liu B, Lu J, Jiang L, Zhang Y, Shen Y, et al. Serum albumin is associated with peripheral nerve function in patients with type 2 diabetes. Endocrine. 2015;50(2):397-404. https://doi.org/10.1007/s12020-015-0588-8.

27. Iwasaki T, Togashi $Y$, Terauchi Y. Significant association of serum albumin with severity of retinopathy and neuropathy, in addition to that of nephropathy, in Japanese type 2 diabetic patients. Endocr J. 2008;55(2):3116. https://doi.org/10.1507/endocrj.K07-086.

28. Chopra JS, Samanta AK, Murthy JM, Sawhney BB, Datta DV. Role of porta systemic shunt and hepatocellular damage in the genesis of hepatic neuropathy. Clin Neurol Neurosurg. 1980:82(1):37-44. https://doi.org/10.101 6/0303-8467(80)90058-X.

29. Dayan AD, Williams R. Demyelinating peripheral neuropathy and liver disease. Lancet. 1967:2(7507):133-4. https://doi.org/10.1016/s0140-673 6(67)92967-4

30. Kardel T, Nielsen VK. Hepatic neuropathy: a clinical and electrophysiological study. Acta Neurol Scand. 1974;50(4):513-26.

31. Apartis E, Leger JM, Musset L, Gugenheim M, Cacoub P, Lyon-Caen O, et al. Peripheral neuropathy associated with essential mixed cryoglobulinemia: a role for hepatitis C virus infection? J Neurol Neurosurg. Psychiatry. 1996;60: 661-6. 
32. David WS, Peine C, Schlesinger P, Smith SA. Nonsystemic vasculitic mononeuropathy multiplex, cryoglobulinemia, and hepatitis C. Muscle Nerve. 1996;19(12):1596-602. https://doi.org/10.1002/(SICI)1097-4598(199612 )19:12<1596::AID-MUS9>3.0.CO;2-5.

33. Bonetti B, Invernizzi F, Rizzuto N, Bonazzi ML, Zanusso G, Chinaglia G, et al. T-cell-mediated epineurial vasculitis and humoral-mediated microangiopathy in cryoglobulinemic neuropathy. J Neuroimmunol. 1997; 73(1-2):145-54. https://doi.org/10.1016/S0165-5728(96)00191-9.

34. Authier FJ, Bassez G, Payan C, Guillevin L, Pawlotsky JM, Degos JD, et al. Detection of genomic viral RNA in nerve and muscle of patients with HCV neuropathy. Neurology. 2003;60(5):808-12. https://doi.org/10.1212/01.WNL. 0000044399.71601.EA.

35. Karl NG, Lin Cindy S-Y, Nicholas MF, Burroughs AK, Bostock H. Conduction and excitability properties of peripheral nerves in end-stage liver disease. Muscle Nerve. 2007:35:730-8.

36. Gentilini P, La Villa G, Casini-Raggi V, Romanelli RG. Hepatorenal syndrome and its treatment today. Eur J Gastroenterol Hepatol. 1999;1 1(9):1061-5. https://doi.org/10.1097/00042737-199909000-00021.

37. Menon KV, Kamath PS. Regional and systemic hemodynamic disturbances in cirrhosis. Clin Liver Dis. 2001;5(3):617-27. https://doi.org/10.1016/S1089-32 61(05)70184-7.

38. Caraceni P, Domenicali M, Tovoli A, Napoli L, Ricci CS, Tufoni M, et al. Clinical indications for the albumin use: still a controversial issue. Eur J Intern Med. 2013;24(8):721-8. https://doi.org/10.1016/j.ejim.2013.05.015.

39. Navarro JF, Mora C. Role of inflammation in diabetic complications. Nephrol Dial Transplant. 2005;20(12):2601-4. https://doi.org/10.1093/ndt/gfi155.

40. Pazdro R, Burgess JR. The role of vitamin $E$ and oxidative stress in diabetes complications. Mech Ageing Dev. 2010;131(4):276-86. https://doi.org/10.101 6/j.mad.2010.03.005.

41. Sandireddy R, Yerra VG, Areti A, Komirishetty P, Kumar A. Neuroinflammation and oxidative stress in diabetic neuropathy: futuristic strategies based on these targets. Int J Endocrinol. 2014;2014:1-10. https:// doi.org/10.1155/2014/674987.

\section{Publisher's Note}

Springer Nature remains neutral with regard to jurisdictional claims in published maps and institutional affiliations.

\section{Submit your manuscript to a SpringerOpen ${ }^{\circ}$ journal and benefit from:}

- Convenient online submission

- Rigorous peer review

- Open access: articles freely available online

- High visibility within the field

- Retaining the copyright to your article 